\title{
Uma Análise do Padrão de Mudança Técnica na Índia (1974-2014)
}

An Analysis of India's Technical Change Pattern (1974-2014)

\author{
Victor José Rocha de Lima ${ }^{a}$ \\ Andressa Porto Castro ${ }^{b}$ \\ Adalmir Marquetti ${ }^{\mathrm{c}}$
}

Resumo: O presente artigo analisa o padrão de mudança técnica na Índia entre 1974 e 2014. Observa-se um aumento das produtividades do trabalho e do capital para o período como um todo. Contudo, houve três fases de mudança técnica: 1974-1984, 1984-2004 e 20042014. Os primeiros dois períodos houve aumento das produtividades do trabalho e do capital. No terceiro período, houve um padrão de mudança técnica Marx-viesado, que aumenta a produtividade do trabalho e reduz a produtividade do capital. O crescimento econômico na terceira fase foi muito superior ao observado nas anteriores, bem como a redução dos níveis de pobreza.

Palavras-chave: Mudança Técnica; Crescimento Econômico; Produtividade; Desenvolvimento Industrial; Índia.

Classificação JEL: B14; O33; O40.

\begin{abstract}
This article analyzes the pattern of technical change in India between 1974 and 2014. There was an increase in labor and capital productivities, considering the entire period. However, there were three phases of technical change: 1974-1984, 1984-2004 and 2004-2014. The labor and capital productivities increased in first two periods. In the third period, there was a pattern of biased Marx technical change, which increases labor productivity and reduces capital productivity. Economic growth in the third phase was much higher than in the first two phases, as well as the reduction in poverty levels.
\end{abstract}

Keywords: Technical Change; Economic Growth; Productivity; Industrial Development; India

JEL Classification: B14; O33; O40.

\footnotetext{
a Doutorando em Economia do Desenvolvimento pelo programa de pós-graduação em economia do desenvolvimento da Pontifícia Universidade Católica do Rio Grande do Sul. E-mail: victorjrl@live.com.

b Doutoranda em Economia do Desenvolvimento pelo programa de pós-graduação em economia do desenvolvimento da Pontifícia Universidade Católica do Rio Grande do Sul. E-mail: andressaportoc@gmail.com.

${ }^{\mathrm{c}}$ Doutor em Economia pela New School for Social Research e professor titular do programa de pósgraduação em economia do desenvolvimento da Pontifícia Universidade Católica do Rio Grande do Sul. Email: adalmarquetti@gmail.com.
} 


\section{Introdução}

A Índia é um país que ocupa um lugar de destaque no cenário mundial não só por ser um dos países mais populosos do mundo e sua cultura singular, mas em virtude, principalmente, do crescimento expressivo e duradouro que tem apresentado nas últimas décadas. No período pós independência - 1947 - até início da década de 1980, a economia indiana apresentava uma taxa de crescimento discreta, variando entre $2 \%$ a $4 \%$ ao ano. O País apresentava elevados níveis de pobreza e analfabetismo (BANIK; PADOVANI, 2014). O baixo desempenho é atribuído a um cenário que combinava patamares reduzidos de poupança interna e reduzido investimento. A economia era dependente do setor agrícola, o qual passou a dinamizar-se e passou a apresentar taxas maiores de crescimento no início dos anos 1980.

Uma segunda fase do crescimento pode ser observada entre 1984 e 2004, período em que a economia indiana apresentou uma taxa de crescimento média de 5,51\% ao ano, uma melhora quando comparado com a fase de crescimento anterior, entre 1974-1984, em que a média foi de $3,56 \%$ ao ano. O período foi marcado por significativa intervenção do Estado na economia com a adoção da política de substituição de importações. $\mathrm{O}$ período também compreende o início da abertura econômica, nos anos 1990, bem como o aumento do fluxo de capitais externos, reformas econômicas e políticas fiscais expansionistas (BARBOSA; SOUSA, 2008).

Entre 2004 e 2014, observa-se uma outra fase de expansão da economia indiana, quando a taxa de crescimento média atingiu $7,31 \%$ ao ano. Nessa fase foi observada um forte aumento da poupança interna, que em 1990 era cerca de $20 \%$ do PIB e passou para $35 \%$ nos anos 2000 e elevado aumento dos investimentos, que passaram de $20 \%$ do PIB em 1990 para 38\% do PIB a partir de 2006. Observou-se, também, um forte aumento da produtividade do trabalho e queda da produtividade do capital, uma expansão do salário médio real e queda da taxa de lucro bruto. Também houve melhoras nos aspectos relacionados as questões sociais e na qualidade de vida.

Na primeira fase de crescimento a maioria dos lares indianos eram pobres, já no período mais recente a situação inverteu-se com mais da metade dos lares na Índia sendo classificados como de classe média. Além disso, os investimentos na educação básica e superior contribuíram para a redução das taxas de analfabetismo e aumento da mão de obra especializada (BANIK; PADOVANI, 2014; EXTENDED PENN WORLD TABLES 6.0, 2017; PROGRAMA DE DESENVOLVIMENTO DAS NAÇÕES UNIDAS, 2019).

Nas economias capitalistas, como a economia indiana, o crescimento econômico é relacionado com as mudanças tecnológicas. O progresso técnico permite o aumento da produção com a utilização de menores quantidades de insumos. Os efeitos das mudanças tecnológicas vêm sendo discutidos na economia desde os autores clássicos como Adam Smith - a partir do aumento da produtividade com a divisão do trabalho - e David Ricardo, que já em seu trabalho seminal discutia o efeito da substituição entre capital e trabalho na distribuição de renda (MARQUETTI; PORSSE, 2017; MARQUETTI, 2017). 
Para Marx, a mudança técnica está fortemente associada com o crescimento econômico das economias capitalistas. Em sua visão, no capitalismo os métodos de produção são constantemente alterados devido a adoção de novas técnicas de produção em decorrência da busca de lucros acima da média, super lucros, por parte dos capitalistas. Segundo Marx, é a luta de classes entre os trabalhadores e capitalistas sobre o valor adicionado que propicia o surgimento de um sistema de incentivos de adoção de técnicas poupadoras de trabalho e consumidoras de capital. A crescente mecanização do processo produtivo é a forma que o progresso técnico toma nas economias capitalistas. Esse tipo de mudança técnica acarreta o aumento da produtividade do trabalho e a queda na produtividade do capital. Também pode resultar em uma queda na taxa de lucro, quando a distribuição funcional da renda permanece constante. Foley e Michl (1999) denominaram este tipo de mudança técnica como Marx-viesada (MARQUETTI; PORSSE, 2014; MARQUETTI, 2017).

Este padrão de mudança técnica costuma ser observado em países que passaram por processos tardios de industrialização. Os países em desenvolvimento se aproximam da produtividade do trabalho dos países líderes, adotando técnicas de produção intensivas em capital e que envolvem a mecanização da economia. Portanto, durante esse processo ocorre um aumento da produtividade do trabalho devido ao maior emprego de máquinas e equipamentos ao passo que a produtividade do capital se reduz. Assim, realizar análises empíricas sob o arcabouço da teoria clássica-marxiana envolve a análise das produtividades do capital e trabalho, da taxa de lucro e dos efeitos dessa sobre a taxa de acumulação (MARQUETTI; PORSSE, 2014; MARQUETTI, 2017).

O presente estudo tem por objetivo analisar o padrão de progresso técnico na Índia entre 1974 e 2014 e nas três fases de crescimento, que compreendem os anos 1974-1984 para a primeira fase, 1984-2004 para a segunda fase e a terceira fase entre 2004 e 2014. Para tal objetivo, será adotado o procedimento sugerido por Foley e Michl (1999) e Foley e Marquetti (1999), que consiste em analisar o comportamento das produtividades do capital e do trabalho ao longo do tempo com o uso da relação de distribuiçãocrescimento. Essa relação permite analisar as variáveis associadas a mudança técnica, ao crescimento e a distribuição funcional da renda ao longo do tempo. Para melhor compreender a evolução das variáveis econômicas em estudo a análise incorpora fenômenos políticos, econômicos e sociais da história da Índia.

O estudo está organizado em cinco seções, além desta introdução. A segunda seção ocupa-se de explicar a relação de distribuição-crescimento que permite analisar os padrões de progresso técnico. A terceira seção analisa dos padrões de mudança técnica nas três fases da economia indiana. A quarta seção discute a lucratividade, a distribuição de renda e a mudança técnica. Já a quinta seção discorre sobre a acumulação de capital e o progresso técnico. Por fim, a sexta seção conclui o trabalho e aponta os principais resultados. 


\section{Um Sistema para Investigar a Mudança Técnica}

Para estudar o progresso técnico, utilizamos a relação de distribuição-crescimento que possibilita visualizar a mudança técnica ao longo do tempo. Diversos estudos utilizam esse procedimento para analisar o progresso técnico, entre eles os desenvolvidos por Foley e Michl (1999), Foley e Marquetti (1999), Marquetti (2002), Ferretti (2008), Felipe, Laviña e Fan (2008) e Marquetti e Porsse (2014).

Num dado período, temos que: $\mathrm{X}$ é o PIB; $\mathrm{K}$ é o estoque líquido de capital fixo mensurados na mesma unidade que o PIB; $\mathrm{C}$ é o consumo agregado que inclui todos as despesas menos o investimento bruto; I é o investimento bruto; $\mathrm{D}$ é a depreciação; $\mathrm{N}$ é o número de trabalhadores empregados; $\mathrm{W}$ é a remuneração total dos trabalhadores; $\mathrm{Z}=\mathrm{X}$ - W é o lucro bruto; $\mathrm{R}=\mathrm{Z}$ - D é o lucro líquido; e $\mathrm{Y}=\mathrm{X}-\mathrm{D}$ é o produto líquido.

Entende-se que, para investigar a evolução de uma economia ao longo do tempo, é preferível utilizar medidas relativas ao invés de absolutas. Logo, $\mathrm{x}=\mathrm{X} / \mathrm{N}$ é o PIB por trabalhador ou a produtividade do trabalho, $\mathrm{k}=\mathrm{K} / \mathrm{N}$ é o capital por trabalhador ou intensidade do capital, $\mathrm{w}=\mathrm{W} / \mathrm{N}$ é o salário real médio, $\mathrm{c}=\mathrm{C} / \mathrm{N}$ é o consumo social por trabalhador e $\mathrm{i}=\mathrm{I} / \mathrm{N}$ é o investimento por trabalhador. As outras variáveis são expressas em termos do estoque de capital fixo: $\mathrm{p}=\mathrm{X} / \mathrm{K}=\mathrm{x} / \mathrm{k}$ é o produto por unidade do capital ou produtividade do capital; $\mathrm{v}=\mathrm{Z} / \mathrm{K}=\mathrm{z} / \mathrm{k}$ é a taxa de lucro bruto; $\mathrm{r}=\mathrm{v}$-d é a taxa de lucro líquido; $g_{k}+\mathrm{d}=\mathrm{I} / \mathrm{K}$ é a taxa de acumulação de capital ou a taxa de crescimento do estoque de capital; $\mathrm{d}=\mathrm{D} / \mathrm{K}$ é a taxa de depreciação. As taxas de crescimento das produtividades do trabalho e do capital são, respectivamente, $g_{x}=\Delta x / x$ e $g_{\mathrm{p}}=\Delta p / p$. A parcela do lucro da renda nacional é $\pi=z / x$ e a parcela salarial é $1-\pi=\mathrm{w} / \mathrm{x}$.

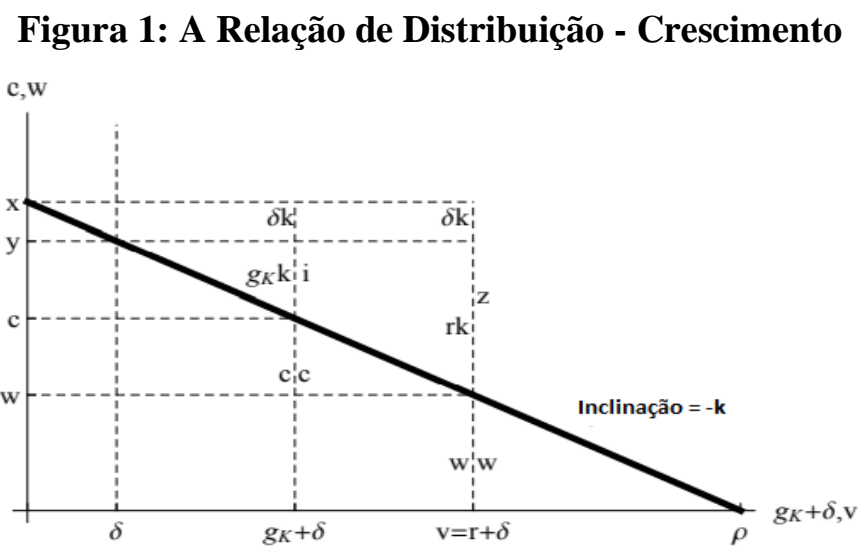

Fonte: Elaboração própria.

Para um dado período, essas medidas podem ser representadas com o uso da relação distribuição-crescimento, que pode ser observada na Figura 1. O ponto $\left(g_{k}+\mathrm{d}, \mathrm{c}\right)$ 
representa a alocação da produtividade do trabalho entre consumo e investimento, temos que: $x=c+i=c+g_{k} k+d k=c+\left(g_{k}+d\right) k$. Quando todo o PIB é investido, a taxa de acumulação atinge seu ponto máximo, o qual é igual à produtividade do capital. Por outro lado, o consumo social por trabalhador é igual a produtividade do trabalho quando o PIB é inteiramente consumo. Já o ponto $(\mathrm{r}+\mathrm{d}, \mathrm{w})$ mostra a alocação da produtividade do trabalho entre salários e lucros, temos que: $x=w+z=w+r k+d k=w+(r+d) k$. Quando o salário total for igual ao PIB, a taxa bruta de lucro é igual a zero e salário real é igual a produtividade do trabalho. Por sua vez, a taxa de lucro máxima será igual a produtividade do capital quando o lucro for igual ao PIB.

A partir da relação de distribuição-crescimento é possível investigar as mudanças técnicas e padrões de crescimento ao longo do tempo (Foley e Michl, 1999). A tecnologia é o conjunto de todas as técnicas de produção conhecidas. A técnica de produção é expressa em termos de produtividade do trabalho, produtividade do capital e da taxa de depreciação. Assim, o padrão de mudança técnica é analisado com base no comportamento destas variáveis. A relação de distribuição-crescimento permite investigar os diferentes padrões de progresso técnico no tempo.

Uma mudança técnica é dita puramente poupadora de trabalho, ou Harrod-neutra, se aumenta a produtividade do trabalho e mantém constante a produtividade do capital. Uma mudança técnica é puramente poupadora de capital, ou Solow-neutra, se aumenta a produtividade do capital e mantém constante a produtividade do trabalho. Uma mudança técnica igualmente poupadora de trabalho e de capital é denominada de progresso técnico Hicks-neutro. As figuras 2, 3 e 4 representam as mudanças técnicas Harrod-neutro, Solow-neutro e Hicks-neutro respectivamente.

\section{Figura 2: A Mudança Técnica Harrod-Neutra}

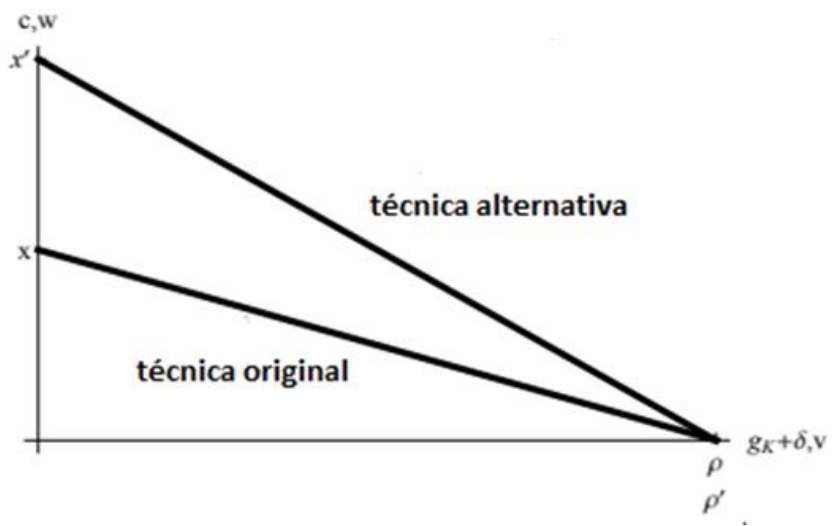

Fonte: Elaboração própria. 


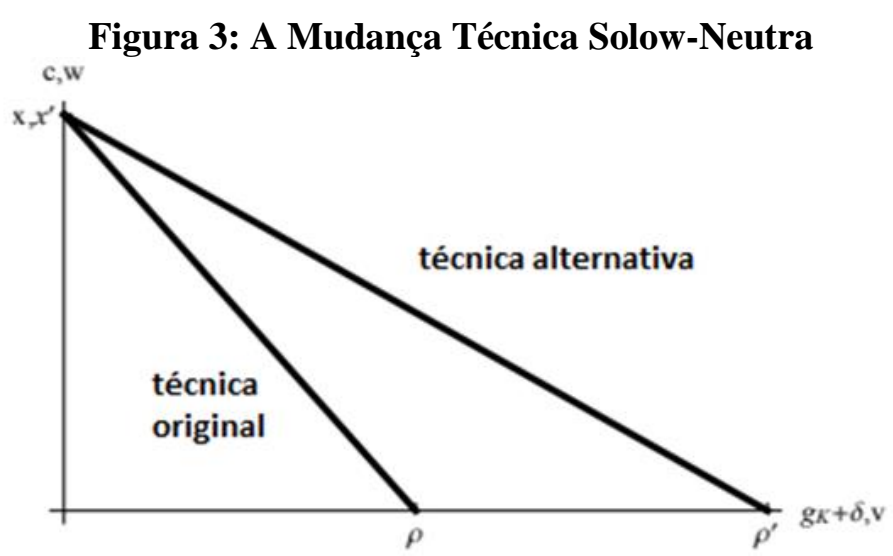

Fonte: Elaboração própria.

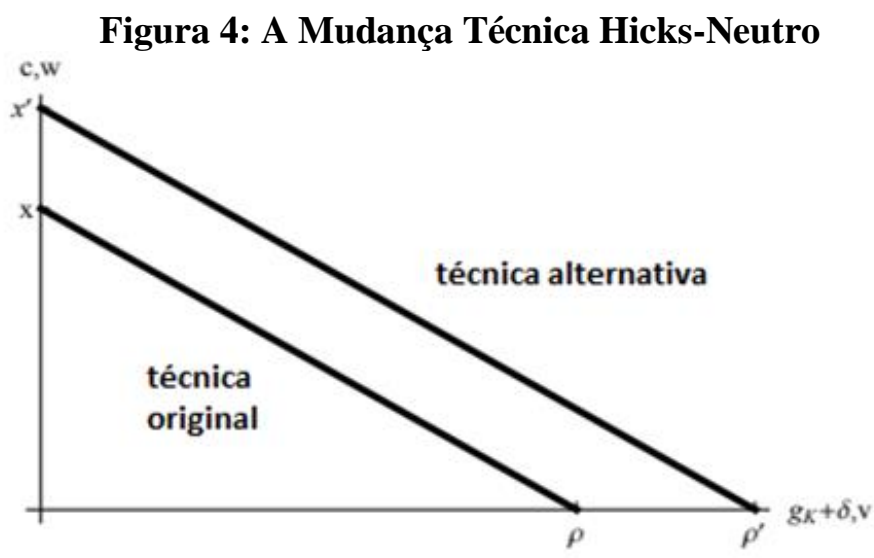

Fonte: Elaboração própria.

Outra possibilidade de mudança técnica é a expressa na figura 5 que é caracterizada como poupadora de trabalho e utilizadora em capital, isto é, eleva a produtividade do trabalho e reduz a produtividade do capital. Esse tipo de mudança técnica é denominado por Foley e Michl (1999) como mudança técnica Marx-viesada. Marx relacionou o desenvolvimento capitalista com o progresso técnico, ou seja, no capitalismo a forma de produção é modificada constantemente a partir de inovações técnicas, de forma a garantir uma lucratividade acima da média para o capitalista inovador. Na visão marxiana, a mecanização do processo produtivo é o progresso técnico típico das economias capitalistas, o aumento da produtividade do trabalho é obtido por meio do maior emprego de máquinas e equipamentos o que reduz a produtividade do capital (MARQUETTI; PORSSE, 2017). 


\section{Figura 5: Mudança Técnica Marx-Viesada}

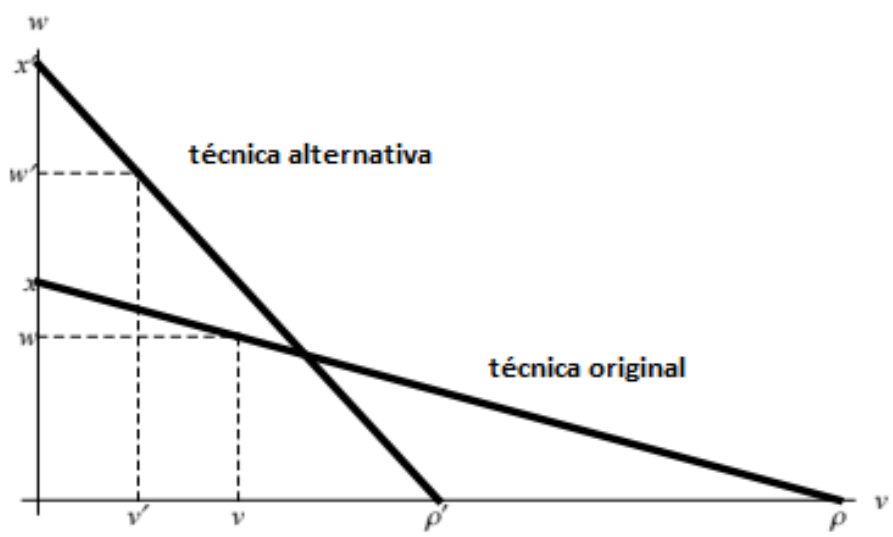

Fonte: Elaboração própria.

O padrão de progresso técnico Marx-viesado ocorre, em particular, nas economias que estão passando por um processo de industrialização - isto é, que apresentam ou estão apresentando um aumento da participação do emprego industrial no emprego total, dos produtos industriais na composição das exportações, elevação da parcela do produto industrial no produto total e rápido crescimento do valor adicionado manufatureiro por trabalhador. Conforme Marquetti e Porsse (2014), uma mudança técnica Marx-viesada apresenta as seguintes tendências de longo prazo: i) aumento da produtividade do trabalho, queda na produtividade do capital e aumento na intensidade do uso do capital; ii) declínio da taxa de lucro, mantida a parcela salarial relativamente constante; iii) aumento do salário real; iv) queda na taxa de acumulação de capital; v) aumento do produto e do emprego.

\section{Mudança Técnica na Índia (1974-2014)}

A figura 6 mostra a relação de crescimento-distribuição da Índia e as fases de mudança técnica compreendidas no período 1974 a 2014 (1974-1984, 1984-2004 e 20042014). O anexo apresenta as informações sobre a fonte dos dados e a metodologia empregada para calcular as variáveis apresentadas no trabalho. Entre 1974 e 2014, observou-se crescimento na produtividade do trabalho da ordem de $3,47 \%$ ao ano, enquanto a produtividade do capital apresentou crescimento de $0,4 \%$ ao ano (EXTENDED PENN WORLD TABLES 6.0, 2017). Por sua vez, a relação capital trabalho aumentou em 3\% ao ano. Portanto, para o período como um todo verifica-se um progresso técnico que foi poupador de trabalho e de capital. 


\section{Figura 6: Índia: A relação de crescimento-distribuição e fases da mudança técnica: 1974-1984, 1984-2004, 2004-2014 (INR 2011)}

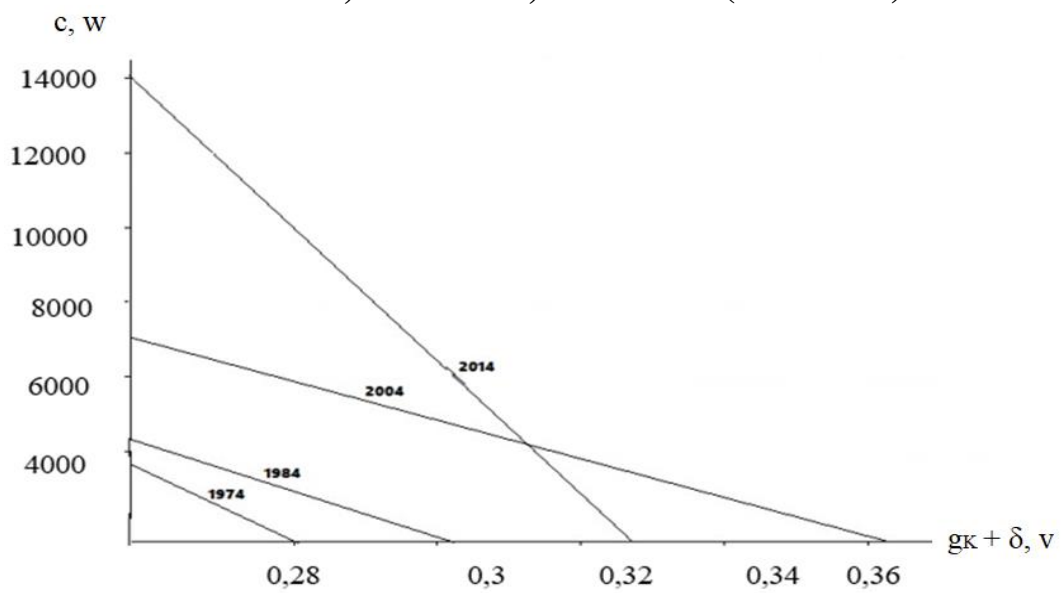

Fonte: Elaboração própria, a partir da utilização do software Stata 12.0.

Entretanto, ainda de acordo com a figura 6, é possível observar o comportamento da produtividade do trabalho e capital em três fases distintas do progresso técnico na economia indiana. A primeira fase compreende o período de 1974 até 1984, quando ocorreu elevação da produtividade do trabalho e do capital na ordem de 1,9\% ao ano e de $0,8 \%$ ao ano respectivamente. Nesse período a taxa de crescimento média da economia indiana girou em torno de 3,56\% ao ano. Vale ressaltar que este baixo desempenho está relacionada com a seca prolongada que destruíram as colheitas entre 1979 e 1980, ao segundo choque do petróleo em 1979, além de elevadas taxas de juros média real no período, na ordem de 6,05\% ao ano. Durante o primeiro período, a economia indiana foi caracterizada por forte exportação de produtos primários e, posteriormente de manufaturados intensivos em recursos naturais ou trabalho. Ademais, a Índia enfrentava neste período um grave quadro social: apenas $40 \%$ da população acima dos 15 anos era alfabetizada em 1981; 88\% da população, em 1977, vivia com menos de 3 dólares e 20 centavos por dia; e um índice de desenvolvimento que figurava entre um dos índices mais baixos do mundo em 1980 (NASSIF, 2006; BANCO MUNDIAL, 2019; EXTENDED PENN WORLD TABLES 6.0, 2017; PROGRAMA DE DESENVOLVIMENTO DAS NAÇÕES UNIDAS, 2019).

Na segunda fase, entre 1984 e 2004, observou-se taxa de crescimento média da economia da ordem de $5,15 \%$ ao ano. A produtividade do trabalho apresentou crescimento de $2,8 \%$ ao ano, ao passo que a produtividade do capital revelou uma expansão de $1 \%$ ao ano. Vale ressaltar a crise de liquidez em 1991, advindo do padrão de crescimento relacionado aos entraves na gestão do financiamento e do balanço de pagamento, o que levou a Índia a recorrer a empréstimos do FMI sob a condição de 
adoção de uma política mais orientada para o mercado. De maneira geral, a política prómercado tinha como objetivo reduzir a inflação e os déficits em conta corrente (FELIPE, KUMAR \& ABDON, 2010; NASSIF, 2006; EXTENDED PENN WORLD TABLES 6.0, 2017; LELLIS, 2018). Nesta fase, praticou-se a maior taxa de juros média real no comparativo com os outros dois períodos, 7,02\% ao ano (BANCO MUNDIAL, 2019). Esse período também ficou marcado pelos seguintes fatos:

1) A transição para o fím do modelo de substituição de importação (NASSIF, 2006; LELLIS, 2018);

2) Reformas econômicas, como o plano quinquenal, iniciado a partir de 1985, que tinha como objetivo elevar as taxas de crescimento, geração de empregos e melhoria do bemestar social, uma política industrial voltada para a expansão da produtividade e eficiência econômica, combinando a atuação do estado forte com o setor privado (PLANNING COMMISSION, 2014);

3) Enfoque no comércio exterior e no câmbio, atração de investimento estrangeiro direto (IED), robustez no sistema financeiro e mercado de capitais (NASSIF, 2006);

4) Houve melhora no quadro social indiano: o percentual da população alfabetizada acima dos 15 anos saltou de $40 \%$ em 1981 para 48\% em 1990; o percentual da população que vivia com menos de 3 dólares e 20 centavos passou de $88 \%$ em 1977 para $81 \%$ em 1993; o IDH aumentou de 0,36 em 1980 para 0,42 em 1990 (BANCO MUNDIAL, 2019; PROGRAMA DE DESENVOLVIMENTO DAS NAÇÕES UNIDAS, 2019).

A terceira fase compreende o período de 2004 até 2014, quando a taxa de crescimento média da economia foi de 7,31\%. Observou-se, também, aumento da produtividade do trabalho da ordem de $11,4 \%$ ao ano, enquanto a produtividade do capital apresentou recuo da ordem de $1,3 \%$ ao ano. Destaca-se, ao longo deste período, os seguintes pontos: expansão do gasto público em relação ao PIB apresentando um padrão de investimento voltado para o setor de serviços sociais e comunitários; a menor taxa de juros média real no comparativo com os outros dois primeiros períodos de 3,54 porcento ao ano; rápido crescimento das exportações, sobretudo exportações envolvendo o setor terciário moderno, onde o país passou a ser referência internacional de serviços em CTI; investimentos privados financiados pela expansão do crédito privado; crescimento da participação de máquinas e equipamentos na parcela de importação pós 2010-2011, o que mostra a elevada formação bruta de capital fixo no período que liderava pelo investimento em indústrias de máquinas e equipamentos. Além disso, o quadro social da Índia apresentou rápido avanço nessa fase: o percentual da população acima dos 15 anos alfabetizadas saiu de $48 \%$ em 1990 para 69,3\% em 2011; o percentual da população que vive com menos de 3 dólares e 20 centavos passou de $81 \%$ em 1993 para $60 \%$ em 2011; e o IDH saltou de 0,42 em 1990 para 0,618 em 2014 (NASSIF, 2006; EXTENDED PENN WORLD TABLES 6.0, 2017; LELLIS, 2018; BANCO MUNDIAL, 2019; PROGRAMA DE DESENVOLVIMENTO DAS NAÇÕES UNIDAS, 2019).

Na Figura 7 é possível observar a passagem gradual da economia indiana de uma economia agrária e pouco sofisticada para uma economia de indústria e serviços. No comparativo de 1974 para 2014, a participação da agricultura no PIB regrediu cerca de 
21\%, a participação da indústria no PIB cresceu aproximadamente 5\% e a participação dos serviços expandiu em mais de $16 \%$, destacando a expansão do setor de serviços tecnológicos, como mencionado anteriormente. Observa-se que, mesmo depois da adoção dos programas neoliberais no início da década de 90, a indústria continuou a ganhar espaço na participação do PIB.

\section{Figura 7: Índia: Composição do PIB (1974 - 2014)}

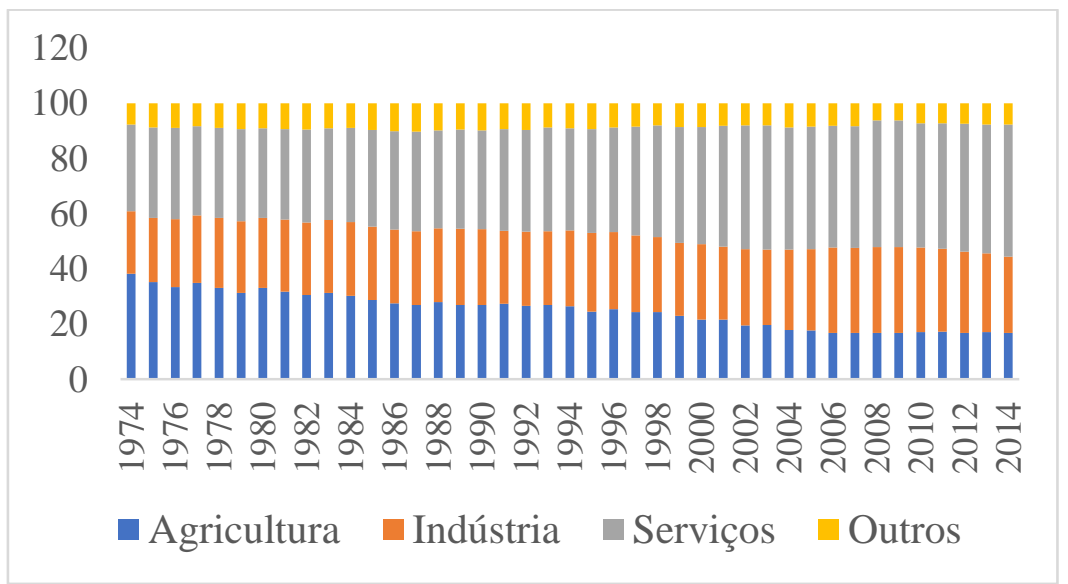

Fonte: Elaboração própria a partir de dados extraídos do Banco Mundial (2019).

Na figura 8, ao observarmos a composição das exportações da economia indiana para o mesmo período, visualiza-se crescimento do setor de serviços, do setor de equipamentos e automóveis, setor químico e queda da participação do setor de alimentos. A Índia expandiu sua capacidade produtiva nos setores de média e alta tecnologia, sobretudo na indústria automobilística, farmacêutica e de tecnologia da informação na terceira fase de progresso técnico.

A indústria automobilística, durante a terceira fase (2004-2014), registrou um dos crescimentos mais rápidos do mundo. Algumas empresas indianas possuem elevada capacidade tecnológica e de inovação, em 2008 a empresa Tata Motors projetou e desenvolveu o carro mais barato do mundo (Tata Nano) e no mesmo ano a empresa adquiriu as marcas Jaguar e Land Rover da Ford Motor Company. Em 2014, a Î́ndia figurou como um dos cinco maiores produtores de veículos do mundo (GALA, 2019).

As indústrias de TI também apresentaram capacidade de geração de tecnologia, atratividade de capital estrangeiro e foram a principal fonte do crescimento econômico no terceiro período em questão (NASSIF, 2008; NASSIF, 2016). Segundo Virmani (2002), a forte expansão do setor de serviços está relacionada com a transformação deste segmento, a qual foi estimulada pelo aumento das exportações de serviços tecnológicos e de engenharia, além de ter sido guiada pelo satisfatório desempenho dos segmentos de serviços empresariais, telecomunicações e bancos. Ainda de acordo com Virmani (2002), o setor de serviços tecnológicos pode ser considerado o polo dinâmico que sustentou o crescimento no período compreendido entre 2004 e 2014. 
Figura 8: Índia: Exportações por setor mensuradas em dólar (1974-2014)

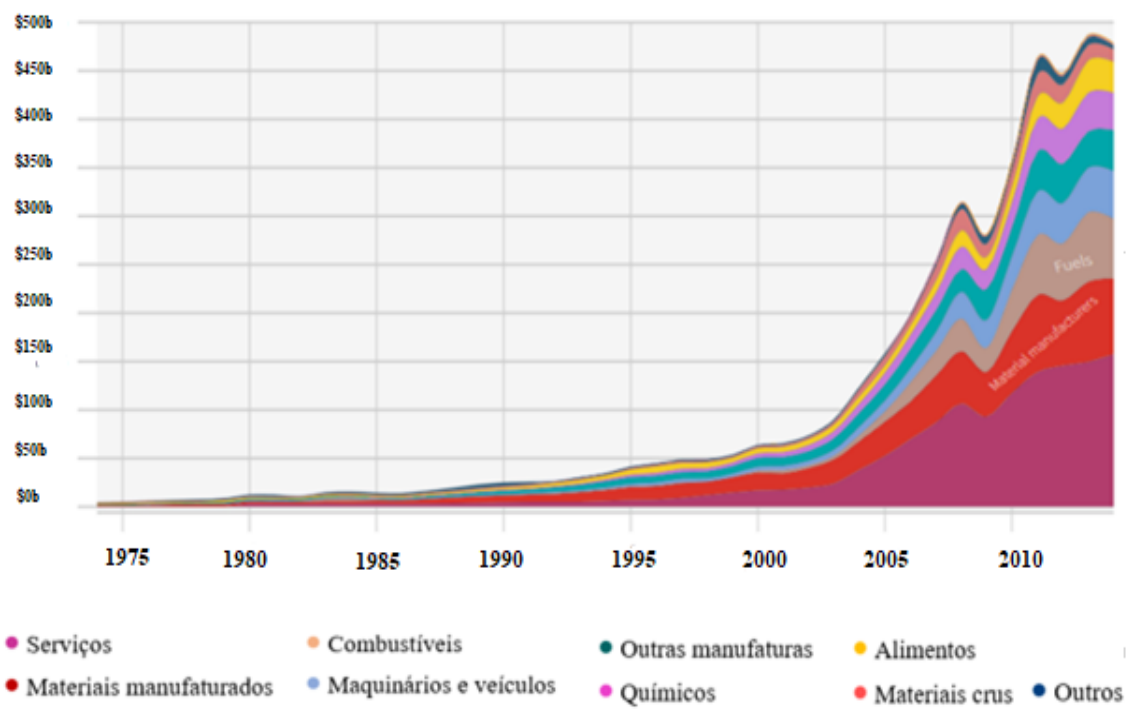

Fonte: Elaboração própria a partir do The Atlas of Economic Complexity (2019).

É possível observar, na figura 9, a evolução da produtividade do trabalho nos três períodos em questão. Verifica-se período com baixo crescimento de 1974 a 1984, de maior crescimento entre 1984 e 2004 e de rápida expansão no período de 2004-2014. É possível observar queda da produtividade do trabalho em 1979 com a segunda crise do petróleo e novamente em 1991, momento em que se iniciou a adoção de medidas liberais na economia.

Figura 9: Índia: Produtividade do trabalho (valores constantes a preços nacionais de 2011) 


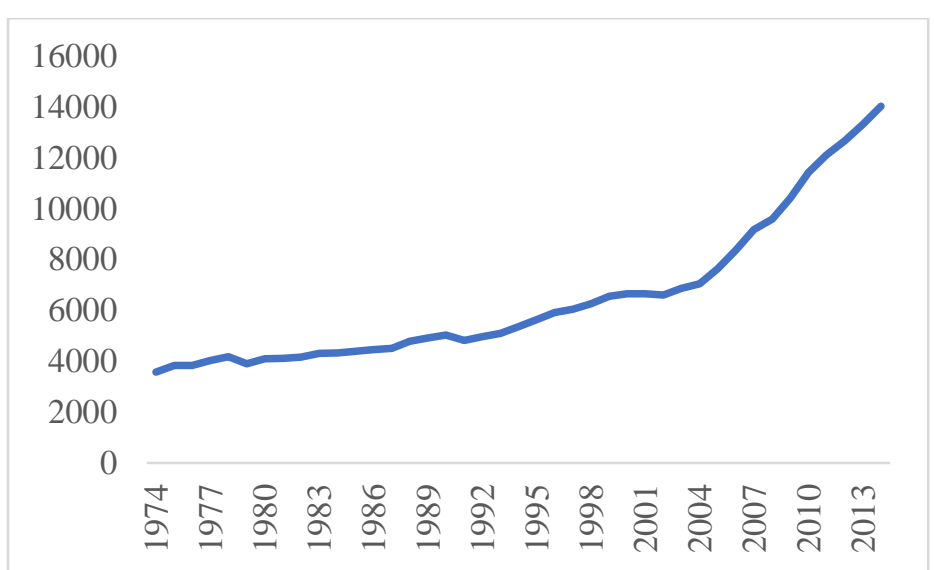

Fonte: Elaboração própria a partir de dados extraídos da Extended Penn World Tables 6.0 (2017).

O padrão de mudança técnica com viés de Marx inicia-se a partir de 2004, na terceira fase, em virtude dos mencionados planos de governo com o objetivo de expansão da estrutura produtiva e apoio ao investimento privado. Foi nesse período em que a economia indiana teve rápida expansão em setores mais intensivos em conhecimento. Esse tipo de mudança técnica é o padrão típico dos países atrasados durante o processo de aproximação ao país líder (MARQUETTI, 2003; FOLEY, MICHL e TAVANI, 2018). Também foi nessa fase que se observou rápida redução de pobreza na Índia.

De acordo com Marquetti e Porsse (2014), o padrão de mudança técnica está relacionado a um processo histórico por meio do qual um país é capaz de descobrir novos métodos de produção ou se beneficiar da transferência das técnicas desenvolvidas em outros países. Os países com industrialização tardia incorporam as técnicas empregadas nos países centrais. As novas técnicas não são um bem público, sendo assim, a utilização dessas técnicas implica em um custo de aquisição e possíveis retardos na sua utilização pelos países atrasados. Eles também necessitam de acesso a maquinário e equipamento, educação da força de trabalho e um período de aprendizado pelas firmas e trabalhadores. Porém, empregar técnicas desenvolvidas em países líderes é mais fácil e rápido do que descobrir novas maneiras de produzir (FOLEY \& MICHL, 1999; MARQUETTI, 2003; MARQUETTI \& PORSSE, 2014).

\section{Lucratividade, Distribuição e Progresso Técnico}

Segundo a abordagem clássica-marxiana, o principal vetor capaz de estimular a mudança técnica é a lucratividade. De acordo com esta perspectiva, os capitalistas iriam adotar mudanças técnicas que reduzissem os custos de produção a preços e salários correntes para obterem uma taxa de lucro acima da média com a venda de seus produtos a preços estabelecidos por competidores menos eficientes tecnicamente. Entretanto, é a luta entre o capital e o trabalho pela distribuição do valor adicionado que explica a forma tomada pela mudança técnica na sociedade capitalista. A mecanização substitui o trabalho 
humano por máquinas e equipamentos no processo de produção, elevando a produtividade do trabalho (FOLEY; MICHL, 1999; MARQUETTI, 2003; MARQUETTI \& PORSSE, 2014; VILLANUEVA; JIANG, 2018). Okishio (1961) pontuou, ainda, que se os salários reais permanecessem inalterados, a taxa de lucro tenderá a crescer mesmo se o progresso técnico for Marx-viesado. A queda da taxa de lucro requer que a distribuição de renda permaneça relativamente constante.

É possível mensurar a taxa de lucro pela razão entre o total de lucro gerado em um período e o capital investido no processo de produção. Deve-se relembrar que apenas uma parte dos lucros totais é apropriada pelos capitalistas. As outras parcelas do valor adicionado são destinadas aos trabalhadores improdutivos, ao estado e a outros pagamentos (MARQUETTI, 2003; MARQUETTI; PORSSE, 2014). Segundo Duménil e Lévy (1993), há um conjunto de possibilidades de calcular a taxa de lucro, no presente trabalho, a taxa de lucro foi computada da seguinte maneira:

$$
v=\frac{Z}{K}=\frac{\frac{Z}{X}}{\frac{K}{X}}=\pi p=\left(1-\frac{w}{x}\right) p
$$

Onde $\pi$ é a parcela do lucro, $\mathrm{p}$ é a produtividade do capital, w é o salário real médio e x é a produtividade do trabalho. O salário médio real é deflacionado pelo deflator do PIB e representa o custo de um trabalhador sob a ótica do capitalista. O comportamento da taxa de lucro está relacionado aos seguintes fatores: distribuição funcional da renda e produtividade do capital. A distribuição funcional da renda apresenta relação com a evolução do salário médio real relativo à produtividade do trabalho. A parcela do lucro cresce, assim como a taxa de lucro, quando a produtividade do trabalho cresce mais do que o salário médio.

É possível observar, na figura 10, a trajetória da taxa de lucro bruto na Índia no período de estudo a preços nacionais constantes de 2011. Podemos identificar elevação da taxa de lucro de 1974 a 2014. Na primeira fase, entre 1974 e 1984 a taxa de lucro não apresenta uma tendência. Na segunda fase, houve aumento da taxa de lucro. A partir de 2006, a taxa de lucro apresenta tendência de queda.

\section{Figura 10: Índia: Taxa de lucro bruto (valores constantes a preços nacionais de 2011, \%)}




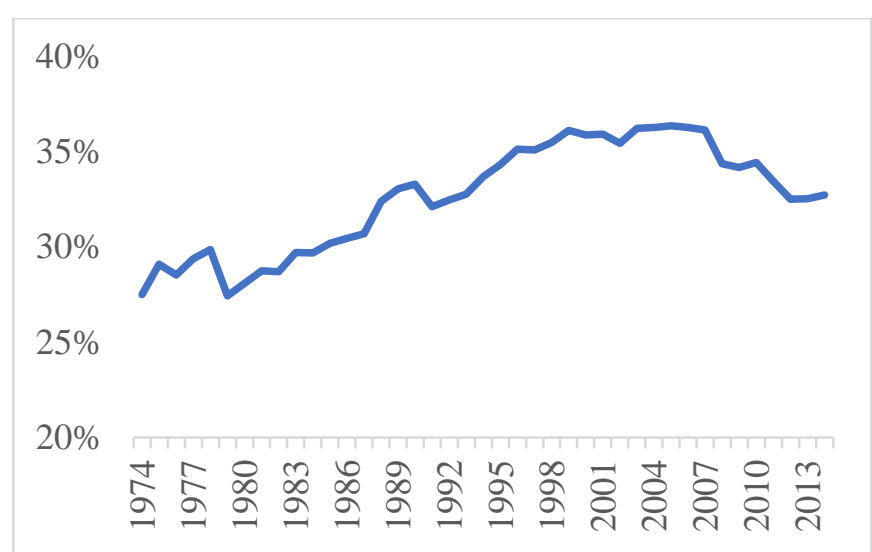

Fonte: Elaboração própria, a partir de dados extraídos da Extended Penn World Tables 6.0 (2017).

Os movimentos na taxa de lucro podem ser explicados por mudanças na distribuição funcional da renda e na produtividade do capital. A Figura 11 mostra queda da parcela salarial entre 1974 e 2014, indicando a produtividade do trabalho cresceu mais rapidamente do que o salário médio real a partir do início dos anos 1980. Contudo, na primeira fase e na terceira fase houve certa estabilidade da parcela salarial. Foi na segunda fase em que a parcela salarial declinou rapidamente.

\section{Figura 11: Índia: Parcela salarial}

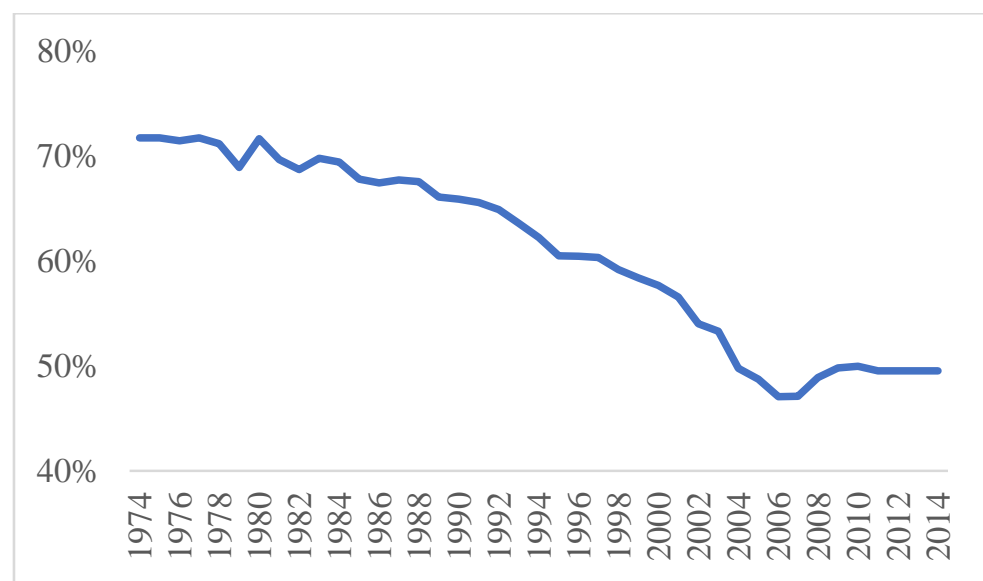

Fonte: Elaboração própria, a partir de dados obtidos na Extended Penn World Tables 6.0 (2017).

A Figura 12 apresenta a produtividade do capital medida a preços nacionais constantes de 2011. Assim, como observado na taxa de lucro, verifica-se três fases distintas na produtividade do capital. No primeiro período, de 1974 até 1984, houve 
crescimento; no segundo período, de 1984 até 2004, ocorreu rápido aumento da produtividade do capital; e, no terceiro período, de 2004 a 2014, houve queda da produtividade do capital. A Figura 12 mostra que no longo prazo, a taxa de lucro acompanhou o comportamento da produtividade do capital, exceto no intervalo entre o início da década de 1990 até 2004, quando a parcela salarial caiu devido ao aumento da produtividade do trabalho a taxas muito superiores ao salário médio real.

Figura 12: Índia: Produtividade do capital (valores constantes a preços nacionais de 2011 mensurados em percentual)

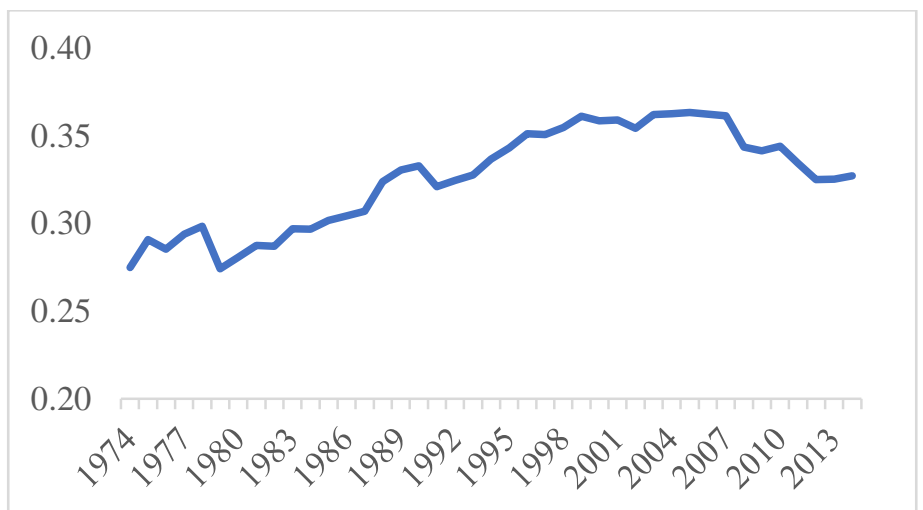

Fonte: Elaboração própria, a partir de dados extraídos da Extended Penn World Tables 6.0 (2017).

\section{Acumulação de Capital, Investimento e Progresso Técnico}

A acumulação de capital mede a velocidade em que o estoque de capital não residencial, que compreende edifícios não residenciais, maquinários e equipamentos, se expande ao longo do tempo. Consequentemente, dado que o trabalho esteja disponível, a acumulação de capital mede a velocidade na qual a capacidade por produção de riqueza do país está crescendo, mantida constante a produtividade do capital. A acumulação de capital é determinada pela taxa de lucro e pela taxa de investimento (MARQUETTI, 2002; MARQUETTI, 2003; MARQUETTI E PORSSE, 2014).

A figura 13 revela que a trajetória de acumulação de capital na Índia também apresentou as três fases que observamos na análise do progresso técnico. Entre $1974 \mathrm{e}$ 1984, ocorreu declínio; no segundo período, entre 1984 e 2004, houve expansão da taxa de acumulação de capital; e, no terceiro momento (2004-2014), a taxa de acumulação de capital teve queda.

Figura 13: Taxa de Acumulação de Capital (1974=100) 


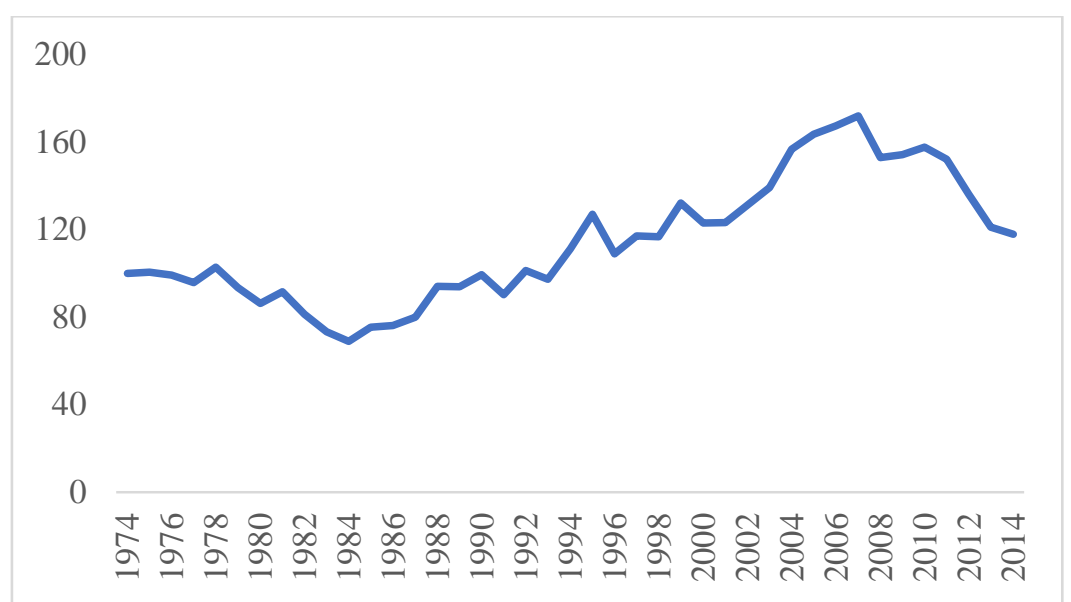

Fonte: Elaboração própria, a partir de dados obtidos pela Extended Penn World Tables 6.0 (2017).

Na figura 14 observa-se que a taxa de acumulação de capital e a taxa de lucro bruto apresentaram comportamentos similares ao longo do tempo. É possível verificar, no início dos anos 1980, que a taxa de lucro bruta começou a aumentar, enquanto a taxa de acumulação de capital declinou até 1986. Foi a partir da segunda fase que a taxa de acumulação e a taxa de lucro tiveram movimentos similares. $\mathrm{O}$ aumento da taxa de lucro ocasionou a expansão da taxa de acumulação. A partir de 2006, no terceiro período, houve queda na taxa de lucro e, por consequência, na taxa de acumulação.

A figura 15 mostra as trajetórias da taxa de acumulação de capital e da taxa de investimento no período em estudo. Observa-se que a queda da taxa de acumulação no começo da década de 1980 decorreu do declínio da taxa de investimento. Foi a partir de meados dos anos 1980 até o início dos anos 2000, que corresponde a segunda fase, que a taxa de investimento teve uma expansão moderada. A taxa de investimento aumentou rapidamente na terceira fase até 2012, quando passou a diminuir. Os resultados mostram que a taxa de acumulação de capital na Índia foi determinada pelas taxas de lucro e de investimento.

Figura 14: Índia: Taxa de acumulação de capital e taxa de lucro bruto (1974=100) 


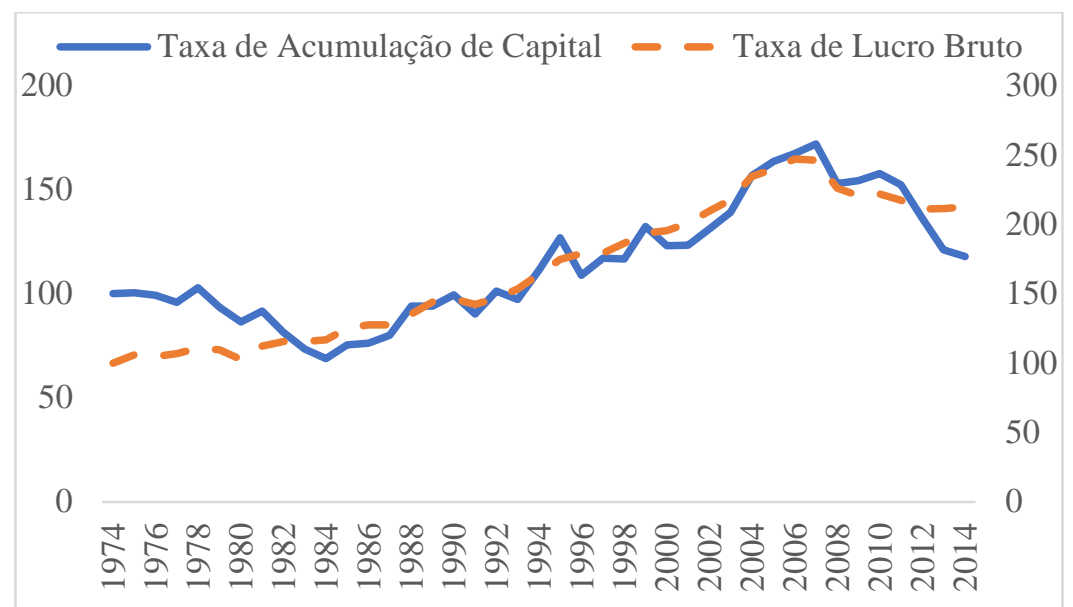

Fonte: Elaboração própria, a partir de dados extraídos da Extended Penn World Tables 6.0 (2017).

Figura 15: Índia: Taxa de acumulação de capital e taxa de investimento (1974=100)

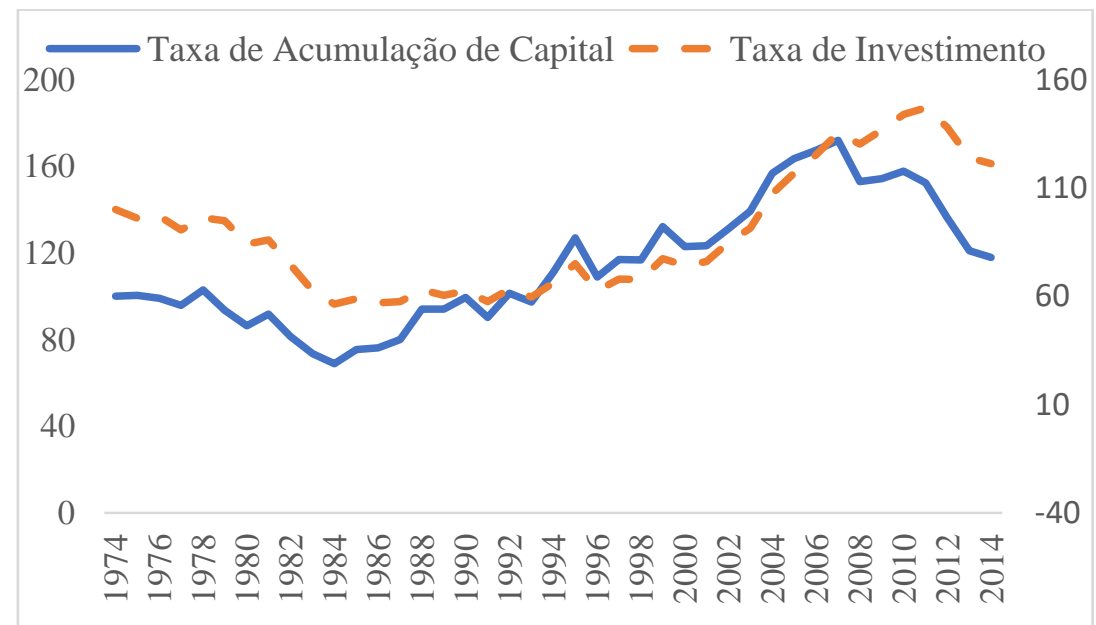

Fonte: Elaboração própria, a partir de dados extraídos da Extended Penn World Tables 6.0 (2017).

\section{Considerações Finais}

Ao observarmos a evolução da mudança técnica na Índia entre 1974 e 2014 observou-se aumento das produtividades do trabalho e do capital, bem como a presença de três fases de progresso técnico (1974 a 1984, 1984 a 2004 e 2004 a 2014). Nas duas 
primeiras fases, a economia indiana apresentou um padrão de mudança técnica poupadora de trabalho e de capital. Na terceira houve um padrão de mudança técnica Marx-viesado. Foi nessa fase que a economia indiana apresentou maiores taxa de crescimento do PIB e maior redução do nível de pobreza na Índia.

A fase inicial, compreendida entre 1974 e 1984, houve ligeiro aumento da taxa de lucro e declínio da taxa de acumulação devido a redução da taxa de investimento. A fase compreendida entre 1984 e 2004 foi marcada por maior crescimento econômico, aumento da taxa de acumulação devido a expansão da taxa de lucro e da taxa de investimento. No período de 2004 até 2014 a economia indiana apresentou um padrão de mudança técnico Marx-viesado, com aumento da produtividade do trabalho e declínio da produtividade do capital. Com a estabilização da parcela salarial, houve queda da taxa de lucro. A taxa de acumulação diminui com a queda da taxa de lucro e a redução da taxa de investimento. Apesar da terceira etapa ter representado um crescimento muito elevado, as quedas da taxa de lucro e da taxa de investimento indicam limites para o modelo de crescimento indiano.

O presente estudo é trabalho inicial sobre a economia indiana e aponta para a necessidade de se realizar estudo histórico das políticas econômicas e sociais no País. A importância econômica e social da Índia irá aumentar no futuro e melhor entendimento da economia indiana é fundamental para compreendermos os caminhos que os países em desenvolvimento seguem em seu processo de desenvolvimento.

\section{Anexo - Base de Dados e Metodologia}

Este apêndice apresenta as fontes dos dados e o procedimento adotado para o cálculo das varáveis utilizada no trabalho. Os dados referentes à produtividade do trabalho, produtividade do capital taxa de lucro bruto, salário médio real e investimento por trabalhador foram obtidos na Extended Penn World Tables 6.0 (2017). A taxa de acumulação de capital bruta foi construída a partir da razão investimento por trabalhador e capital por trabalhador, medidos a preços nacionais constantes de 2011. A taxa de juros média real foi colhida na base de dados do Banco Mundial (2019). O índice de alfabetização, porcentagem da população que vive com menos de 3 dólares e 20 centavos por dia e foram colhidos na base de dados do Banco Mundial (2019), já o índice de desenvolvimento humano foi colhido na base de dados do Programa de Desenvolvimento das Nações Unidas (2019).

\section{Referências Bibliográficas}

BANCO MUNDIAL. Disponível em: https://datos.bancomundial.org/pais/india. Acesso em 5 de dezembro de 2019. 
BANIK, A.; PADOVANI, F. Índia em Transformação: O novo crescimento econômico e as perspectivas pós-crise. Revista de Sociologia e Política, v. 22, n. 50, p. 67-93, 2014. DOI: https://doi.org/10.1590/1678-987314225006

BARBOSA, M. M.; SOUZA, N. J. Impactos das Reformas Liberalizantes dos Anos 1980 e 1990 sobre a Economia Indiana. Revista de Desenvolvimento Econômico, v. 10, p. 133-144, 2008.

DUMÉNIL, G.; LÉVY, D. The Economics of the Profit Rate: Competition, crises, and historical tendencies in capitalism. Edward Elgar, 1993.

EXTENDED PENN WORLD TABLES. Disponível em:

https://sites.google.com/a/newschool.edu/duncan-foley-homepage/home/EPWT. Ed.

2017. Acesso em 6 de dezembro de 2019.

FELIPE, J.; KUMAR, U.; ABDON, A. M. Exports, Capabilities, and Industrial Policy in India. Bard College Levy Economics Institute Working Paper, n. 638, 2010.

DOI: https://dx.doi.org/10.2139/ssrn.1713848

FELIPE, J.; LAVIÑA, E.; FAN, E. X. The Diverging Patterns of Profitability, Investment and Growth of China and India during 1980-2003. World Development, v. 36, n. 5, Elsevier, 2008.

FERRETTI, F. Patterns of Technical Change: A geometrical analysis using the wageprofit rate schedule. International Review of Applied Economics, v. 22, n. 5, 2008. DOI: https://doi.org/10.1080/02692170802287581

FOLEY, D.; MARQUETTI, A. Productivity, Employment and Growth in European Integration. Metroeconomica, v. 50, n. 3, 1999.

DOI: https://doi.org/10.1111/1467-999X.00074

FOLEY, D. K.; MICHL, T. R. Growth and Distribution. Cambridge: Harvard University Press, $1^{\mathrm{a}}$ ed. 1999.

FOLEY, D. K.; MICHL, T. R. Growth and Distribution. Cambridge: Harvard University Press, $2^{\mathrm{a}}$ ed. 2018.

GALA, P. O Incrível Avanço da Indústria Automotiva na Índia. Paulo Gala/Economia \& Finanças, São Paulo, 04 de jul. 2019. Disponível em: https://www.paulogala.com.br/oincrivel-avanco-da-industria-automotiva-na-india/. Acesso em: 7 de dez. 2019.

LELLIS, C. S. Índia: Crescimento pós-reformas. Dissertação de Mestrado em Economia - Programa de Pós-Graduação em Economia (PPGE), Instituto de Economia, Universidade Federal do Rio de Janeiro. Rio de Janeiro, 2018.

MARQUETTI, A. Progresso Técnico, Distribuição e Crescimento na Economia Brasileira: 1955-1998. Estudos Econômicos, v. 32, n. 1, p. 103-124, 2002. 
MARQUETTI, A. Analyzing Historical and Regional Patterns of Technical Change from a Classical-Marxian Perspective. Journal of Economic Behavior \& Organization, v. 52, n. 2, Elsevier, 2003. DOI: https://doi.org/10.1016/S0167-2681(03)00021-0

MARQUETTI, A., PORSSE, M. Patterns of Technical Progress in the Brazilian Economy, 1952-2008. CEPAL Review, v. 113, p. 57-73, 2014.

MARQUETTI, A.; PORSSE, M. Padrões de Mudança Técnica nas Economias LatinoAmericanas: 1963-2008. Economia e Sociedade, v. 26, n. 2, p. 459-482, 2017.

DOI: https://doi.org/10.1590/1982-3533.2017v26n2art7

NASSIF, A. A Economia Indiana no Período 1950-2004 da Estagnação ao Crescimento Acelerado: Lições para o Brasil. Texto para discussão, n. 107, Rio de Janeiro, BNDES, 2006.

OKISHIO, N. Technical Change and the Rate of Profit. Kobe University Economic Review, v. 7, 1961.

PLANNING COMMISSION. National Plans: Five Year Plans. Vários anos. Disponível em: <http://planningcommission.gov.in/plans/planrel/index.php?state=planbody.htm>. 2014.

PROGRAMA DE DESENVOLVIMENTO DAS NAÇÕES UNIDAS. Disponível em: https://www.in.undp.org/. Acesso em 5 de dezembro de 2019.

SHIHAI, S. Estratégias de Desenvolvimento e Desempenho Econômico da Índia. In: GUIMARÃES, S. P. Estratégias Índia e Brasil. Rio de Janeiro: IPRI, 1997.

VILLANUEVA, L.; JIANG, X. Patterns of Technical Change and Deindustrialization. PSL Quarterly Review, v. 71 n. 285, p. 161- 182, 2018. DOI: https://dx.doi.org/10.13133/2037-3643_71.285_4

VIRMANI, A. Sources of India's Economic Growth. Working Paper no. 131. New Delhi: Indian Council for Research on International Economic Relations-ICRIER. 2002. 